\title{
Análise da APAC de Pouso Alegre - MG na Percepção dos Dirigentes e Recuperandos
}

\section{Analysis of the APAC of Pouso Alegre - MG in the Perception of Managers and Recoveries}

\author{
Claudio Roberto Fernandes
}

Universidade Federal de Itajubá, Programa de Pós-Graduação Stricto Sensu em Administração. MG, Brasil. Instituto Federal de Educação, Ciência e Tecnologia do Sul de Minas Gerais. MG, Brasil.

E-mail: drclaudiorobertofernandes@gmail.com

\begin{abstract}
Resumo
A Associação de Proteção e Assistência aos Condenados - APAC, surge como alternativa a execução da pena no cárcere convencional, promovendo a humanização da pena e possibilitando assim o retorno digno do preso a sociedade, através da disciplina, profissão, escolaridade e religiosidade que possibilitam a transformação do preso em nova pessoa. O problema é as poucas APACs instaladas para tantos interessados, considerando que os detentos requerem ter seu cumprimento de pena em uma dessas unidades, que, infelizmente são insuficientes. Essa pretensão dos presos se justifica porque enquanto no sistema convencional eles ficam ociosos na maior parte do tempo, sem acompanhamento médico, psicológico e odontológico, na APAC o cenário é totalmente diferente. Dessarte, este trabalho objetivou analisar a APAC de Pouso Alegre - MG, pela percepção dos seus dirigentes e recuperandos, sobre as dificuldades, desafios e resultados. A metodologia de pesquisa científica escolhida foi de natureza exploratória e descritiva, abordando o método qualitativo. Concluiu-se que as APACs são juridicamente legais, respaldadas pela Constituição da República de 1988 e pela Lei de Execução Penal na busca de parâmetros legais para a ressocialização dos recuperandos, promovendo a dignidade do ser humano e a humanização da pena, reduzindo em cerca de cinco vezes a chance de reincidência pelos recuperandos da APAC, onde esses presos saem da instituição com seus estudos concluídos, profissionalizados e humanamente evoluídos, saindo para a liberdade felizes, inclusive na maioria das vezes empregados em padarias e supermercados de Pouso Alegre que tem convênio e priorizam empregar os egressos da APAC.
\end{abstract}

Palavras-chave: APAC. Humanização. Pena Alternativa. Pouso Alegre.

\begin{abstract}
The Association for the Protection and Assistance of Convicts - APAC, emerges as an alternative to the execution of the sentence in the conventional prison, promoting the humanization of the sentence and thus enabling the dignified return of the prisoner to society, through the discipline, profession, education and religiosity that enable the transformation of the prisoner into a new person. The problem is that there are few APACs installed for so many interested parties, considering that detainees require that they serve their sentences in one of these units, which, unfortunately, are insufficient. This claim of the prisoners is justified because while in the conventional system they are idle most of the time, without medical, psychological and dental care, in APAC the scenario is totally different. Therefore, this work aimed to analyze the APAC of Pouso Alegre - MG, by the perception of its leaders and recovering people, about the difficulties, challenges and results. The chosen scientific research methodology was exploratory and descriptive in nature, addressing the qualitative method. It was concluded that the APACs are legally legal, supported by the Constitution of the Republic of 1988 and the Law of Penal Execution in the search for legal parameters for the resocialization of the recovered, promoting the dignity of the human being and the humanization of the penalty, reducing by about five times the chance of recidivism by the APAC recoveries, where these prisoners leave the institution often with studies, professionalized, and humanly evolved, leaving for freedom happily, including most often employed in bakeries and supermarkets in Pouso Alegre, which has an agreement and prioritize employing APAC graduates.
\end{abstract}

Keywords: APAC. Humanization. Alternative Penalty. Pouso Alegre.

\section{Introdução}

O Sistema Prisional do País cada vez mais questionado sobre a atualidade das leis, a eficácia das prisões, a corrupção dos servidores da justiça e os erros de investigação e do judiciário, entre outros questionamentos, traz uma crescente aversão ao que é certo e muitas vezes algumas pessoas com essa revolta somada a pobreza comete crimes, na sua maioria não violentos e ligados ao consumismo.

Dessa forma pergunta-se: o cerceamento da liberdade do indivíduo, da forma que é feito hoje, é suficiente para ressocializá-lo dando condições de que retorne a sociedade melhor que quando foi preso?

No entanto, em que pese a possibilidade de mudanças, surge a Associação de Proteção e Assistência aos Condenados - APAC, como alternativa a execução da pena no cárcere convencional, promovendo a humanização da pena e possibilitando assim o retorno digno do preso ao convívio social, através da disciplina, profissão, escolaridade e religiosidade que possibilitam a transformação do preso comum em nova pessoa, com chance de reincidência cinco vezes menor que no sistema comum 
Diferente do método de prender e castigar, as APAC visam, por meio de metodologia específica, reinserir na sociedade as pessoas que ali se encontram e que são chamadas de recuperandos (ao invés de detentos). Concedendo dignidade e possibilidade - que não existe no sistema comum - de terem nova vida através do estudo, trabalho, religião e disciplina, promovendo a humanização da pena, possibilitando assim o retorno digno do preso ao convívio social.

E não é por acaso que os presos do sistema comum pedem para cumprir a pena na APAC porque enquanto no sistema convencional ficam ociosos na maior parte do tempo, sem acompanhamento médico, psicológico e odontológico, na APAC não faltam ações que transformam esses recuperandos em seres humanos melhores, por isso o índice de reincidência menor.

Um problema é que apesar da eficácia das APAC existem poucas unidades no país para tantos interessados, haja vista que tão logo tomam conhecimento dessa instituição os detentos peticionam por seus advogados ou de próprio punho aos respectivos juízes da execução penal, pedindo para serem transferidos e cumprir suas penas em uma das unidades, que, infelizmente são insuficientes.

\section{Desenvolvimento}

\subsection{APAC}

Surgiu em 1972, como alternativa ao sistema penitenciário tradicional, idealizada por Mário Ottoboni, a denominada APAC, que significava a princípio "Amando ao Próximo Amarás a Cristo" (MARQUES; STUDART, 2020). Em 1974, ganha personalidade jurídica, tornando-se Associação de Proteção aos Condenados, passando a atuar como Órgão Parceiro da Justiça e da Segurança na execução da pena, iniciando o trabalho no presídio de Humaitá, em São José dos Campos mesmo (LOPES; CLEMENTEL, 2020).

As APACs são filiadas e administradas pela FBAC Fraternidade Brasileira de Assistência aos Condenados, órgão de utilidade pública que fiscaliza e gerencia as APACs.

Informações expostas no relatório sobre as APACs, divulgada pela FBAC (2021) mostra que até o mês de março de 2021, existem 137 APACs espalhadas em território nacional. Números esses que pode ter variações, levando em consideração que nesta informação consta só as instituições oficialmente filiadas a FBAC.

A definição do Tribunal de Justiça de Mato Grosso (2021) é que a APAC trata-se de uma entidade civil de direito privado, com personalidade jurídica própria, dedicada à recuperação e reintegração social dos condenados a penas privativas de liberdade. O trabalho da APAC dispõe de um método de valorização humana, vinculada à evangelização, para oferecer ao condenado condições de recuperar-se. Busca também, em uma perspectiva mais ampla, a proteção da sociedade, a promoção da Justiça e o socorro às vítimas.

Segundo o próprio idealizador, a APAC: “é um método de valorização humana, portanto de evangelização, para oferecer ao condenado condições de recuperar-se, logrando, dessa forma, o propósito de proteger a sociedade e promover a justiça" (OTTOBONI, 2004).

$\mathrm{Na}$ explicação de Ferreira e Ottoboni (2016) a APAC é uma entidade civil de direito privado, sem fins lucrativos, com patrimônio e personalidade jurídica próprios e tempo de duração indeterminado. Cada APAC é autônoma - jurídica, administrativa e financeiramente.

Este modelo de associação penitenciária possui um método fundamentado na garantia dos princípios constitucionais da dignidade da pessoa humana, o respeito a integridade física e moral e pauta-se na aplicação da LEP, pois garante ao apenado assistência psicológica, jurídica, a saúde e a educação tendo como principal objetivo a humanização do sistema prisional possibilitando ao detento novas possibilidades, evitando desta forma a reincidência e possibilitando a efetiva reintegração social (MARQUES; STUDART, 2020).

Uma vez inserido na APAC o cidadão está submetido a uma sequência de hábitos que interferirão no seu pensamento sobre o mundo e sobre si mesmo. Um exemplo é a abordagem fornecida a eles: nenhuma pessoa pode ser apelidado ou ser chamado por nomes pejorativos, podendo apenas ser chamado e reconhecido pelo nome (SIMÕES, 2014).

Tem o objetivo de germinar a sociabilização do tratamento penitenciário, sem esquecer o seu caráter de responsabilização penal. Para isso, o método aplicado tem como pilar 12 elementos fundamentais: participação da comunidade, recuperando ajudando recuperando, trabalho, religião, assistência jurídica, assistência à saúde, valorização humana, família, voluntário e sua formação, Centro de Reintegração Social, mérito e jornada de libertação com Cristo (DEPEN, 2020).

De acordo com Ottoboni (2018), o método apaquiano coloca o ser humano em primeiro lugar e não o criminoso, tendo a vida humana como protagonista, trabalhando e evangelizando o recuperando.

Segundo D’Agostini e Reckziegel (2016) a APAC é um arquétipo de organização penal que se interessa pela dignidade, de sorte que o sujeito condenado pague pelo ato criminoso executado de modo mais justo. Sustentado pela confiança, basta ver a não existência de policiais ou agentes penitenciários no supervisionamento do cumprimento da pena: são os próprios presos os incumbidos pela segurança, alimentação, limpeza e organização do estabelecimento prisional, buscando, com isso, a ressocialização.

A metodologia APAC, é traçada no enaltecimento humano e confiabilidade no apenado, buscando desligar o retrato de pessoa malquista, e conquistando sua recuperação, e adiante, sua reinserção na sociedade, e também de salvaguardar a proteção social pelo aniquilamento do "criminoso" existente, não omitindo as aplicações de punição e contenção (OTTOBONI, 2018; LOPES; CLEMENTEL, 2020). 
Possui como objetivo o não fortalecimento e incentivo a conduta delitiva dos apenados, mas sim verificar o que levou a praticar tais condutas a fim de recuperá-los para proteger a sociedade e socorrer as vítimas para promover a tão esperada justiça (MARQUES; STUDART, 2020). Segundo Ferreira e Ottoboni (2016) seu intenso objetivo é deixar de lado a incredulidade na recuperação dos apenados, por um rumo diferente do sistema atual, através de um recurso terapêutico, provocando a envoltura da comunidade a que retornará o reeducando.

Amparada pela Constituição Federal (BRASIL, 1988) para atuar nos presídios, tem seu estatuto resguardado pelo Código Civil e pela Lei de Execução Penal, a LEP (BRASIL, 1984). Tal metodologia nasce embasada na LEP, acentuando o cumprimento de pena, exercendo a liberdade progressiva, dando prioridade a reeducação do preso (MORAIS, 2017).

Não tem exigências de uma descrição específica para a transferência de um preso para ser admitido em uma APAC. $\mathrm{O}$ preso condenado à pena privativa de liberdade pode ser transferido para uma APAC através de deliberação do Juiz de Execução do foro competente, com a devida análise do parecer emitido pelo promotor de justiça, e apreciado os requisitos: manifestação de interesse em ser transferido por escrito ou em ato processual, devidamente documentado, e se comprometer a se adequar às regras da APAC; possuir vínculos familiares ou sociais, no local onde está instalada a APAC, há no mínimo um ano, independentemente de onde tenha cometido o delito. Cabe ainda ao magistrado competente a criação de novos critérios que julgar cabíveis para segurança dos trabalhos (TJMG, 2017).

Depois de devidamente admitido por uma instituição APAC, dentro da metodologia, existem as fases da adaptação e a da integração. A fase de adaptação refere-se à etapa inicial da vida do recuperando na APAC, já a integração, etapa posterior, compreende o cumprimento da pena em um dos regimes (FERREIRA; OTTOBINI, 2016).

\subsection{APACs em contradição com o Sistema penitenciário comum}

As desigualdades presentes entre o sistema prisional e as APAC evidenciam-se pelas maneiras de preparo da execução da pena. Nos dizeres de Santos (2011): As semelhanças contidas são que os dois lidam com pessoas que cometeram crimes e sofreram sanção penal por parte do Estado. Os parâmetros e condições existentes são complemente divergentes nos dois sistemas. $\mathrm{O}$ autor ainda enfatiza que é como querer comparar o céu com o inferno, onde metaforicamente podemos nos aproximar mais do tema aqui em voga.

Frente aos problemas enfrentados pelo sistema prisional, como a superlotação, e falta de condições mínimas de higiene, de estruturação e organização, Santos (2011) posiciona sobre sua importância econômica, social e política, de vez que se trata de sistema prisional que funciona com no mínimo três vezes menos recursos financeiros, 99\% menos pessoal do serviço público, atendendo igual demanda de sentenciados e com resultados em média setenta vezes melhor do que o sistema convencional.

Ainda no que diz respeito aos custos despendidos pelo Estado, é reconhecido a economia de verba pública que um preso da APAC proporciona em comparação a um preso que vive no sistema comum. Números expostos referentes ao ano de 2019 mostrou que um detento custou para o Estado aproximadamente $\mathrm{R} \$ 1.900,00$ por mês. Consoantes informações da APAC, a média percapita por detento na instituição, até o mês de março de 2021 foi de R $\$ 1.282,66$ por mês. Provando assim, que no sistema APAC sai mais barato custodiar um detento (FBAC, 2021).

Tal economia pode ser justificada por razão do dispêndio com a alimentação ser diminuto, devido às parcerias que as associações têm com empresas, que viabilizam o cultivo de plantações de alimentos, criação de animais, como galinheiros e suinocultura no interior das unidades. Outro motivo advém de que os serviços médicos, odontológicos e psicológicos, entre outros serviços, são prestados de forma gratuita por profissionais voluntários que residem na região (DEMBOGURSKI; OLIVEIRA; DURÃES, 2021).

Sob essa perspectiva, a APAC pode ser notada como uma organização que tende a diminuir as sequelas fomentadas pelo sistema prisional, protelando a prisão para casos extremos.

As circunstâncias pelas quais as casas de detenção brasileiras estão, podem tanto travar quanto fomentar uma determinada cooperação entre os presos, como os agentes, e, em desfecho, existe uma casualidade: a inexistência de uma referência mínima que assegure uma garantia jurídica. $\mathrm{O}$ que preocupa é o perseverante hábito assumido entre detentos e operadores do direito, reivindicando uma intensa modificação cultural, tanto em quem pune quanto no punido (DARKE, 2014); enquanto na APAC, o podemos ver a mudança desta concepção no detido, tal e qual, uma oportunidade de exibir ao povo uma outra perspectiva a respeito da pena, como uma verdadeira utilidade (LOPES; CLEMENTEL, 2020).

O desembargador, Helbert Caneiro, ex-presidente do TJMG, dá sua opinião: “O rigor e a disciplina costumam ser muito mais elevados do que no sistema comum, ainda que as APACs sejam permeadas pelas diretrizes de humanização da pena" (TJMG, 2017).

No discurso de Morais (2017) fica diferenciando a APAC do sistema carcerário comum, o fato que os recuperandos são corresponsáveis pela própria recuperação, além de lhe ser oferecida assistência espiritual, médica, psicológica e jurídica prestada pela comunidade local.

A diferença entre a metodologia APAC e a metodologia prisional tradicional é que, na primeira, os próprios d presos são corresponsáveis pela sua recuperação e têm assistência espiritual, médica, psicológica, e jurídica, oferecidos por voluntariados. Ademais, são oferecidas ao recuperandos formações supletivas e profissionalizantes, podendo eles desempenhar variados serviços, a depender do regime em que 
se encontram, evitando assim a ociosidade. A relação familiar do recuperando, o regulamento inflexível, abrangendo respeito, ordem e valorização humana, também são eminentes razões que distinguem os dois sistemas (CARVALHO; CASTILHO, 2019).

A APAC exibe também como individualidade do sistema, a presença ativa de voluntários, sendo a posição do voluntário como essencial para o desenvolvimento satisfatório das unidades (LIMA; CASTIEL, 2017).

Modificadamente do sistema carcerário habitual, em que os aprisionados realizam só trabalhos artesanais, ocupando-os tão somente como um ramo de terapia ocupacional, na APAC o recuperando desenvolve e pratica uma profissão honesta e lucrativa, lucrando por seu labor e apresentando-se como uma criatura de utilidade à sociedade. Por receber determinada quantia referente ao seu próprio trabalho, vagarosamente, o recuperando vai se sentir proficiente, podendo, até, conceder apoio financeiro à sua família (SILVA, 2012).

O ex presidente do TJMG, Helbert Carneiro, declara: "ao assegurar o direito de estudo e de trabalho a todos os detidos, o que nem sempre é viável no sistema prisional comum, as APACS permitem que o cumprimento da pena seja mais rápido, tendo em vista as remições recorrentes dessas atividades" (TJMG, 2017. Em comparação com prisões típicas do Brasil, estas não concedem respeito as normas da LEP e nem aos direitos fundamentais da pessoa humana, enquanto nas APACs os recintos em que são desenvolvidos este projeto é fadado de boas condições de higiene e bem-estar (CARVALHO; CASTILHO, 2018).

Outra característica presente no sistema da APAC é estranha à maioria dos presídios tradicionais, não só no Brasil como em diversas outras partes do mundo: a ausência de polícia ou de forças armadas dentro das unidades (DEMBOGURSKI; OLIVEIRA; DURÃES, 2021). Esta postura contribui para a mudança na visão que os detentos a respeito do ambiente no qual está inserido, passa-se a ver a instituição como mais acolhedora (ALVES; MIJARES, 2014).

Estima-se que a reincidência entre os egressos das unidades APAC gire em torno de $15 \%$, enquanto no sistema comum alcança o percentual de 70\% (TJMG, 2018).

No discurso de Silva (2012) ele relata sobre a vantagem das APACs sob ponto de vista da reincidência baixa bastando a análise que nas APAC's o índice de reincidência é próximo a $10 \%$, disparado o menor índice do mundo, e com um detalhe importantíssimo, que quando reincidentes, o delito cometido é o mesmo, ou delito de menor potencial ofensivo do que aquele que os levou ao cárcere a primeira vez.

Destaca-se nessa divergência do modelo comum de execução penal, a busca da APAC pela valorização da pessoa por meio do princípio da dignidade humana, com respaldo pressuposto que todos são recuperáveis, possuindo uma tripla finalidade, em que é atuar como coadjuvante da justiça, proteção da sociedade e proteção aos condenados (LIMA; CASTIEL, 2017).

\subsection{Resultados e Discussão}

A unidade APAC atua na cidade de Pouso Alegre - MG há 18 anos na prestação desse relevante serviço social. Esta unidade atualmente conta com 198 recuperandos, sendo que 153 estão sob no regime fechado e 45 no semiaberto. A rotina é tranquila com muito estudo e trabalho.

Ao ser questionado sobre o perfil dos internos no que tange a reincidentes, oriundos do sistema prisional tradicional, foi informado que há expressivo número de recuperandos que estão sob esta condição, com cerca de $60 \%$ reincidentes e $40 \%$ primários.

Já com relação aos egressos da própria APAC de Pouso Alegre, cerca de apenas 17\% voltam a delinquir. Sobre a questão da ressocialização é informado que $83 \%$ dos reeducandos são devidamente ressocializados não voltando a cometer crimes.

Questionado sobre os crimes cometidos pelos recuperandos informa-se que há todo o tipo penal. Sendo que ao menos 50\% são de tráfico de drogas e os outros $50 \%$ roubo, homicídio e estupro.

Inquirido sobre quanto tempo demoram a pedir transferência para cumprimento da pena na APAC, informa-se que tão logo os detentos descobrem sobre essa associação eles pedem transferência, por carta ou pelos seus patronos.

De acordo com os dirigentes da APAC as práticas, ações e mecanismo para a reinserção social desses apenados ocorre principalmente através dos três pilares do método apaquiano: estudo, trabalho e religião. Ali mesmo na fazenda há local próprio para desenvolver esses pilares sem necessidade de se ausentar da instituição.

Segundo a direção da APAC a principal dificuldade no que tange a reinserção do recuperando é a dependência química. A dependência química ao álcool ainda é pior que a das drogas.

A concepção dada a restrição da liberdade proposta pelo sistema é a aplicação da própria LEP e da $\mathrm{CF} / 88$, de acordo com os dirigentes da instituição da cidade de Pouso Alegre MG.

Os elementos essenciais do sistema APAC da unidade de Pouso Alegre é a distribuição dos trabalhos em oficinas profissionalizantes, de acordo com a carga horária de cada um. A distribuição das tarefas diárias é feita pelos próprios recuperandos, frisando-se não haver hierarquia entre eles haja vista todos sem exceção serem de confiança.

Dessa forma se possibilita não só o trabalho, mas os estudos também. Inclusive os próprios recuperandos trabalham na administração, tendo acesso a documentos do judiciário e eles próprios inserem dados nas planilhas e sistemas para atualizar a remição das penas, entre outras atualizações de estudo e trabalho bem como a de participação em todas as atividades programadas pela instituição para os recuperandos.

Inquiridos sobre a participação da sociedade local informou-se que o envolvimento ainda é muito pequeno. Talvez pelo medo, preconceito ou até mesmo pela falta de 
busca de ajuda social pela instituição em si.

Uma das grandes dificuldades enfrentadas ali é a falta de mão de obra de recuperandos nas oficinas do regime semiaberto, onde muitas vezes são usados pessoal do regime fechado, o que não é o correto, mas acaba acontecendo no caso concreto.

Inquirindo os dirigentes sobre a questão religiosa, informam que uma vez por semana, em capela própria ali dentro da APAC, disponibiliza-se horário para orações e culto evangélico. É permitido culto religioso de outra(s) denominação, pois o mais importante é a questão de se acreditar em Jesus e desenvolver o cristianismo, a fim de aplicar o método como é para ser aplicado.

Sobre as questões jurídicas desses recuperandos eles são sim auxiliados pela APAC se estiverem desassistidos. Se esses recuperandos tem advogados eles devem continuar sendo assessorados pelos seus defensores. A defensoria pública atua em parceria com a APAC de Pouso Alegre no que necessita - reiterando, desde que os recuperandos não possuam advogados.

A unidade de Pouso Alegre tem visita assistida de familiares como esposa, filhos, mães e demais membros das suas famílias toda semana, suspendo no momento por conta da pandemia do novo coronavírus (COVID19). As famílias podem se reunir em salas ou numa área interna parecida com uma verdadeira praça, com jardim e com toda a segurança que se precisa.

Ali dentro conta-se com um local de venda de lanches a fim de que as famílias e detentos, querendo, possam se alimentar, além de poderem, claro, entrar com alimentos trazidos de casa.

Indagados sobre se as famílias não poderiam entrar com drogas, armas, celulares e afins disfarçados entre as comidas, os administradores da APAC informam que isso não acontece porque as famílias e os recuperandos tem plena consciência de que se isso ocorrer e for descoberto, o recuperando perde o direito a vaga na APAC e volta ao sistema carcerário tradicional (mesmo caso que ocorre se houver fuga) e como eles tem plena consciência que a APAC é melhor que o sistema comum, todos tem um empenho notável para fazer o que é certo, o que é permitido.

Tem o dia reservado da visita intima que ocorre quinzenalmente. Essa visita íntima não pode ser realizada por outra mulher que não a própria esposa do recuperando. Ou seja: namoradas, garotas de programa e afins não são permitidas. Os quartos para a realização das visitas íntimas são limpos, arejados, com banheiro e com a privacidade minimamente necessária ao fim social a que se destina, se assemelhando a um motel mediano.

Perguntado especificamente sobre a questão da pandemia, quando a cidade de Pouso Alegre esteve na faixa vermelha, as visitas e as saídas foram suspensas. No mais foram e continuam sendo efetuados os protocolos de segurança de praxe apregoados de forma geral a fim de proteger funcionários e recuperandos.

Sobre o custo de um recuperando para a APAC os dirigentes informam que é de cerca um terço do sentenciado no sistema comum. Por exemplo, se o preso custa no sistema convencional R $\$ 3.000,00$, na APAC esse mesmo preço custa $\mathrm{R} \$ 1.000,00$.

Na APAC da cidade de Pouso Alegre consegue aplicar a metodologia criada pelo Dr. Mário Ottoboni, de forma que, os 12 pontos que fundamentam e estrutura a correta aplicação do método é atendida em sua totalidade. Assim foi possível confirmar que os recuperandos têm a participação da comunidade interna e externa de Pouso Alegre e cidades vizinhas através dos cultos e outras atividades, ainda que essa participação não seja assim tão expressiva, mas ela existe.

Cada recuperando ali internado valoriza a vida e o bem-estar dos outros. Diferente das prisões comuns, ali todos estão cuidando uns dos outros, pois se um maltratar ou causar qualquer mal ao próximo é enviado de volta ao sistema carcerário tradicional. Tanto que ali na APAC eles não possuem local diferenciado para estupradores, pedófilos ou quem tem praticado qualquer crime que normalmente não se tolera e os próprios presos acabam torturando e as vezes até matando os delinquentes desses delitos.

$\mathrm{Na}$ APAC todos, independente de seus crimes, tem novas oportunidades, convivendo entre si e cuidando uns dos outros. Praticam o perdão e tem sempre Jesus Cristo como meta, como objetivo e isso permite a prática do perdão e da misericórdia.

Como parte da ressocialização os recuperandos ali na APAC de Pouso Alegre - MG estão trabalhando nos mais variados ofícios, como almoxarifado (armazenamento físico, controle informatizado de estoque), escritórios, oficina de mecânica e de funilaria de carros em geral, padaria, pintura, entre outros trabalhos. Também ressocializam participando das atividades religiosas cristãs, colocando sempre Jesus em primeiro lugar.

Eles têm advogados caso não possam pagar um defensor; tem dentistas e médicos que atendem com consultório médico e odontológico ali dentro; tem a participação da família com uma convivência muito perto deles, acompanhando quase que diariamente a vida dos detentos que têm acesso à comunicação.

Os recuperandos são valorizados como pessoas que são e não bichos, monstros, infratores, enfim, são pessoas, seres humanos, que erraram e que estão ali precisando de uma mão que lhes dê uma chance de vida nova.

Despertou atenção a questão dos estudos que é um ponto levado muito a sério pelo método apaquiano.

Foi relatado um caso ali na instituição de Pouso Alegre onde um recuperando lia a obra indicada e resumia para os outros detentos. Os recuperandos envolvidos nessa trama acreditaram que o professor voluntário que ali prestava esse serviço de interpretação de texto e redação não leria os trabalhos e por isso foi feito esse plágio. Essa atividade 
auxiliava os recuperandos na remição da pena, onde a cada período e quantidade de resumos, remia-se a pena em um dia. Descoberto o caso essa atividade foi cancelada como meio de punir os recuperandos que não souberam aproveitar o benefício concedido de aprender e ainda remir a pena, numa clara demonstração de que a APAC não tolera desonestidade e leva todos os pilares muito a sério, inclusive o estudo em si, nas atividades mais simples.

Essa seriedade da APAC de Pouso Alegre - MG se apresenta em diversas facetas, que chamam muito a atenção de qualquer pessoa por mais distraída que possa parecer.

Nesse caso do processo ensino-aprendizagem, ainda se percebe ambiente muito bem estruturado e convênios que permitem aos recuperandos que ali chegam semianalfabetos, saírem com Diploma de Graduação e até Pós-Graduação. Tudo realizado através do ensino a distância, com internet de qualidade, bons computadores, biblioteca e salas de estudo, reunião e palestras, web conferência e tudo o que a tecnologia pode fornecer a fim de que os recuperandos tenham todas as condições de ter uma formação de qualidade e ao sair dali, seja alguém com Diploma nas mãos, além das profissões que desenvolve ali na prática: padeiros, almoxarife, controlador de estoque, entre outras conforme já mencionado.

Têm ainda local próprio para a prática de esportes diversos como parte do lazer, das práticas de saúde e da disciplina e da convivência entre si.

Chama muito a atenção a limpeza e a organização da instituição de Pouso Alegre, bem como a cordialidade e educação dos recuperandos e funcionários, que não trabalham com armas e truculência. Logo na chegada, a guarita abriga apenas uma pessoa e desarmada apenas para controle da entrada e não para impedir a entrada ou fuga de recuperandos, pois não possuía armas e outros artifícios inerentes aos guardas de guarita de penitenciarias comuns.

Ambiente leve e amigável dessa instituição pousoalegrense, onde certamente é possível afirmar que a presença de Nosso Senhor Jesus Cristo, em primeiro lugar, claro, somado a participação da família, o trabalho, a educação, a valorização como pessoa humana que os recuperandos são em vez de números, estatística, enfim, entre outros, fez toda a diferença na vida de todos que fazem parte da APAC de Pouso Alegre, recuperandos, funcionários e até visitantes pesquisadores como eu que ficou fascinado com o trabalho ímpar dessa instituição penal.

\subsubsection{Percepção do Recuperando $\mathrm{R} 1$ em relação à $\mathrm{APAC}$}

R1 tem entre 46 e 53 anos de idade, é solteiro, branco, não tem filhos e possui ensino médio completo. Sua renda familiar é entre um e dois salários. O R1 é católico e não há parentes envolvidos em crimes. Não é usuário de substâncias ilícitas ou lícitas como álcool e cigarros. Antes de ser preso era trabalhador da indústria.

Indagado sobre o tempo que está recluso informa que a mais de cinco anos e que os delitos praticados foram roubo, tráfico, formação de quadrilha e receptação. Que se encontra arrependido. Sobre sua situação processual encontra-se condenado e é reincidente do sistema comum pela primeira vez, mas nunca havia estado na APAC antes.

Diz que sempre quis trabalhar no período de sua ressocialização. Ainda informa sobre as vantagens da APAC com relação ao sistema prisional convencional, como por exemplo a possibilidade de pagar a pena com ausência de conflitos, ter atendimento médico e odontológico, possuir assistência jurídica, poder contar com o apoio da família, viver num ambiente de respeito mútuo, com condições de reflexão sobre os erros cometidos, com disciplina, higiene, tratamento humano de todos envolvidos, acesso à cultura, arte e educação, disponibilidade de psicólogos, lazer, ocupação profissionalizante e estudo, entre outros.

Na opinião do R1 através da APAC é promovida verdadeira ressocialização dos recuperandos. Dentre os vários benefícios da APAC Pouso Alegre, a remição da pena, a ocupação e a profissionalização são entre outras as que mais se destacam. R1 avalia com o conceito de ótima as ações da APAC de Pouso Alegre na reeducação e reinserção social dos sentenciados, não encontrando ponto negativo para criticar.

\subsubsection{Percepção do Recuperando $\mathrm{R} 2$ em relação à $\mathrm{APAC}$}

R2 tem entre 18 e 25 anos de idade, é solteiro, pardo, não tem filhos e possui ensino médio completo. Sua renda familiar é acima de cinco salários. O R2 é evangélico e não há parentes envolvidos em crimes. Não é usuário de substâncias ilícitas ou lícitas como álcool e cigarros. Antes de ser preso trabalhava sem profissão definida em qualquer coisa que aparecesse.

Indagado sobre o tempo que está recluso informa que há cerca de três anos e que os delitos praticados foi formação de quadrilha para diversos delitos. E informa que se encontra arrependido. Sobre sua situação processual encontra-se condenado e não é reincidente do sistema comum e que nunca havia estado na APAC antes.

Trabalha com todo tipo de serviços manuais desde que chegou aqui. Ainda informa sobre as vantagens da APAC com relação ao sistema prisional convencional, como por exemplo a possibilidade de pagar a pena com ausência de conflitos, ter atendimento médico e odontológico, possuir assistência jurídica, poder contar com o apoio da família, viver num ambiente de respeito mútuo, com condições de reflexão sobre os erros cometidos, com disciplina, higiene, tratamento humano de todos envolvidos, acesso a cultura, arte e educação, disponibilidade de psicólogos, lazer, ocupação profissionalizante e estudo, entre outros.

Na opinião do R2 através da APAC é promovida verdadeira ressocialização dos recuperandos, com vários benefícios como regenerar-se de verdade, remir a pena, aprender um ofício e desenvolver a religião, o que inclusive o R2 fez questão de informar que é ótima. O R2 avalia com o conceito de ótima as ações da APAC de Pouso Alegre na reeducação e reinserção social dos sentenciados, não encontrando ponto negativo para 
criticar.

\subsubsection{Percepção do Recuperando $\mathrm{R} 3$ em relação à APAC}

O R3 tem entre 46 e 53 anos de idade, é casado, curso superior completo, branco, tem entre um e três filhos, com renda entre um e dois salários, sendo evangélico e não tem familiares envolvidos em crimes. Diz que não é usuário de substâncias ilícitas ou lícitas como álcool e cigarros. Antes de ser preso era advogado e está recluso há menos de um ano. $\mathrm{O}$ crime cometido foi de corrupção e sua situação processual é de condenado. É a primeira vez que comete um crime na vida. Desenvolve diversos trabalhos na APAC.

Assim como os entrevistados anteriores, o R3 deu praticamente a mesma resposta, informa que as maiores vantagens de cumprir a pena na APAC em comparação ao sistema prisional convencional, entre outras coisas, é a oração de manhã, os louvores, o pagamento da pena em paz, ou seja, com ausência de conflitos, tendo atendimento médico e odontológico, assistência jurídica, apoio da família, ambiente limpo, organizado, de respeito mútuo, com condições de reflexão sobre os erros cometidos, com disciplina, humanizado, com acesso a cultura, arte e educação, onde quem não terminou os estudos tem que terminar (ensino médio) e há disponibilidade de através de ensino EaD, o recuperando estudar e sair dali com um curso superior completo, além de acompanhamento psicólogo/ psiquiátrico, lazer, entre vários outros pontos positivos.

$\mathrm{Na}$ opinião do R3 através da APAC é promovida verdadeira ressocialização dos recuperandos, dados estáticos demonstram que enquanto no sistema convencional cerca de $70 \%$ dos egressos do sistema reincidem, na APAC 15\%. De acordo com a percepção do R3, não há críticas a fazer sobre o método apaquiano ou sobre a instituição de Pouso Alegre e avalia, portanto, com a nota máxima, descrevendo com conceito de ótima as ações desse método e dessa unidade.

\section{Conclusão}

A metodologia da APAC estima pelo apreço ao cidadão humano, tendo como objetivo a humanização das instituições carcerárias, sem ignorar a sua destinação de punir. E conforme é possível observar nos formulários aplicados na APAC de Pouso Alegre - MG, os gestores e recuperandos encontram satisfação e gratidão no método do Dr. Mário Ottoboni, que cuida do condenado, de uma forma simplesmente, por tão somente aplicar a CF/88 e a LEP conseguindo a difícil e gratificante tarefa de ressocializar o condenado.

\section{Referencias}

ALVES, I.B.; MIJARES, J.M. Associação de Proteção e Assistência ao Condenado (APAC): conexão local. 2014. Disponível em: <https://pesquisa-eaesp.fgv.br/sites/gvpesquisa. fgv.br/files/conexao-local/relatorio_conexao_local_apac.pdf $>$ Acesso em: 15 abr. 2021.

BRASIL, Lei $n^{\circ}$ 7.210, de 11 de julho de 1984. Institui a Lei de Execução Penal. Disponível em: < http://www.planalto.gov.br/ ccivil 03/leis/17210.htm> Acesso em 13 abr. 2021.

BRASIL Constituição da República Federativa do Brasil. 1988. Disponível em: <http://www.planalto.gov.br/ccivil_03/ constituicao/constituicao.htm> Acesso em: 13 abr. 2021.

CARVALHO, N.L.; CASTILHO, L.V. Importância do método APAC na prevenção terciária e na ressocialização do apenado. Âmbito Jurídico. 2019. Disponível em: <https://ambitojuridico. com.br/cadernos/direito-penal/importancia-do-metodo-apac-naprevencao-terciaria-e-na-ressocializacao-do-apenado/> Acesso em: 15 abr. 2021.

CNJ - Conselho Nacional de Justiça. Reentradas e reinterações infracionais: um olhar sobre os sistemas socioeducativo e prisional brasileiros. Brasília: CNJ, 2019. Disponível em: $<$ https://www.cnj.jus.br/wp-content/uploads/2020/01/Panoramadas-Reentradas-no-SistemaSocioeducativo.pdf.> Acesso em: 14 abr. 2021.

D'AGOSTINI, C.; RECKZIEGEL, R. O método APAC e a humanização do sistema penitenciário brasileiro. Rev. Síntese Direito Penal Proc. Penal, v.16, 2016.

DARKE, S. Comunidades prisionais auto administradas: o fenômeno APAC. Rev. Bras. Ciênc. Criminais, v.107, p.357-376, 2014.

DEMBOGURSKI, L.S.S.; OLIVEIRA, D.D.; DURÃES, T.F.N. Análise do processo de ressocialização: o método da Associação de Proteção e Assistência a Condenados. Rev. Ciênc. Soc., v. 34, n. 48, p.131-154, 2021,

DEPEN - Departamento Penitenciário. Tribunal de Justiça e Sejusp inauguram Apac em Visconde do Rio Branco, na Zona da Mata. Minas Gerais, 2020. Disponível em: <http://www. depen.seguranca.mg.gov.br/index.php/noticias-depen-mg/3680tribunal-de-justica-e-sejusp-inauguram-apac-em-visconde-dorio-branco-na-zona-da-mata> Acesso em 13 abr 2020.

FBAC - Fraternidade Brasileira de Assistência aos Condenados. Relatório sobre as APACs - Data: 14/04/2021. Disponível em: $<$ http://www.fbac.org.br/infoapac/relatoriogeral.php $>$ Acesso em: 14 abr. 2021.

FERREIRA, V.; OTTOBONI, M. Método APAC: Sistematização de Processos. - Belo Horizonte: Tribunal de Justiça do Estado de Minas Gerais, Programa Novos Rumos, 2016. Disponível em: $<$ https://bd.tjmg.jus.br/jspui/bitstream/tjmg/7821/1/APAC.pdf $>$ Acesso em: 13 abr. 2021.

LIMA, T.N.E.; CASTIEL, S. Associação de proteção e assistência ao condenado (APAC) como meio de execução penal. In: CONGRESSOACADÊMICO, v.1,2017. Disponível em: $<$ https:// www.fcr.edu.br/ojs/index.php/anaiscongdireitoconstitucional/ article/view/164> Acesso em: 16 abr. 2021.

LOPES, P.S.O.; CLEMENTEL, F.K. O método APAC: um estudo sobre a eficácia da alternativa à crise do sistema carcerário brasileiro. Porto Alegre: PUC/RS, 2020.

MARQUES, T.S.T.; STUDART, L. APAC: A concretização de um sistema penitenciário humanizado. Rev. Episteme Transversalis, v.11, n.1, p.138-154, 2020.

MORAIS, M. Aplicado em Minas, método Apac é uma das soluções para sistema penitenciário. Conjur. 2017. Disponível em: $\quad<$ https://www.conjur.com.br/2017-fev-26/marcia-moraismetodo-apac-solucao-sistema-penitenciario\#_ftnref1> Acesso em: 15 abr. 2021.

OTTOBONI, M. Vamos matar o criminoso. São Paulo: Paulinas, 2004.

OTTOBONI, M. Vamos matar o criminoso? Método APAC. Belo Horizonte: O Lutador, 2018. 
SANTOS, B-H.P. Ressocialização dos Apenados: análise da atuação da associação de proteção e assistência aos condenados - APAC - no município de Alfenas/ MG. Machado: FUMESC, 2014.

SANTOS, E.O. Aplicação da metodologia da associação de proteção e assistência ao condenado (APAC) no sistema penal comum. 2011. Disponível em: http://www2.forumseguranca. org.br/content/aplica $\% \mathrm{C} 3 \% \mathrm{~A} 7 \% \mathrm{C} 3 \% \mathrm{~A} 3$ odametodologia-daassocia-e-assistancia-ao-condenado-apac-no-sistem. Acesso em: 14 abr. 2021.

SILVA, J.R. A execução penal à luz do método APAC. 2012. Disponível em: <https://www.passeidireto.com/ arquivo/76630363/livro-a-execucao-penal-a-luz-do-metodoapac> Acesso em: 14 abr. 2021.

SIMÕES, A.F.A. Dinâmica de cooperação no sistema prisional: a ótica dos gestores da Associação de Proteção e Assistência aos Condenados (APAC). Salvador: Universidade Federal da Bahia. 2014.
TJMG - Tribunal de Justiça de Minas Gerais. Programa Novos Rumos. 2018. Disponível em: <https://www.tjmg.jus.br/ lumis/portal/file/fileDownload.jsp?fileId=8A80E40A64666AED01646709B2837B67 > Acesso em: 13 abr. 2021.

TJMG - Humanizar a pena e recuperar o condenado. Plural. 2017. Disponível em: <https://www.tjmg.jus.br/portal-tjmg/ noticias/plural/edicao-01.htm\#> Acesso em: 15 abr. 2021.

TJMG - Portaria Conjunta $n^{\circ} 653 / \mathrm{PR} / 2017$. Estabelece normas para a transferência de presos em cumprimento de pena privativa de liberdade para os Centros de Reintegração Social - CRS, geridos pelas Associações de Proteção e Assistência aos Condenados APACs. Disponível em: < http://www8.tjmg.jus.br/institucional/ at/pdf/pc06532017.pdf> Acesso em: 15 abr. 2021.

TJMT - Tribunal de Justiça de Mato Grosso. O que é APAC? Disponível em: <https:/www.tjmt.jus.br/INTRANET.ARQ/ CMS/GrupoPaginas/105/1020/APAC.doc > Acesso em 13 abr. 2021. 